\title{
Analysis of modern approaches to the organization of parking areas in major cities
}

\author{
Lyubov Manukhina ${ }^{1, *}$ \\ ${ }^{1}$ Moscow State University of Civil Engineering, Yaroslavskoye sh., 26, 129337, Moscow, Russia
}

\begin{abstract}
This article is devoted to the study of the most urgent problem of large megacities such as acute shortage of free areas and an acute shortage of parking spaces. Modern methods of solving this problem are considered, foreign experience is learned and practical examples of mechanized multilevel parking in different countries. Currently, most of the residential property, as well as hotels and business centers are being built with standard parking spaces. During the operation of such parking lots, the developer understands that the number of parking spaces provided is significantly less than the number of cars that want to leave their car in the parking lot. The shortage of free parking spaces and parking spaces for parking lots significantly increases the importance of building and arranging multi-level parking lots. The system of high-altitude automatic parking lots offers a serious alternative to the generally accepted ideas about parking of vehicles.
\end{abstract}

\section{Introduction}

The necessity and feasibility of building high-rise mechanized parking for cars is due to the acute problem of temporary and permanent storage of vehicles in terms of cities, in areas of intensive flows of people, such as the central part of the city, supermarkets, railway stations, shopping malls and business centers and residential sector of the city [1]. Also the urgency is caused also by economic expediency and efficiency of application of the innovative parking equipment allowing essentially to reduce quantity of $\mathrm{m} 2$ of the ground allocated for construction of such objects that in turn will allow to provide more effective use of the free areas in city center. The use of innovative technologies to create multi-level parking allows you to place more cars on a smaller area, thereby increasing the efficiency of land use by 9.5 times.

According to the available data (shown in Fig. 1), motorization of the population in Russia (including Moscow) is much lower than in the US and EU countries, however, constant steady growth is observed. Thus, for effective management of the parking space in a metropolis, it is necessary to take into account the constant growth dynamics of these indicators [2].

\footnotetext{
*Corresponding author: 4804107@mail.ru
} 


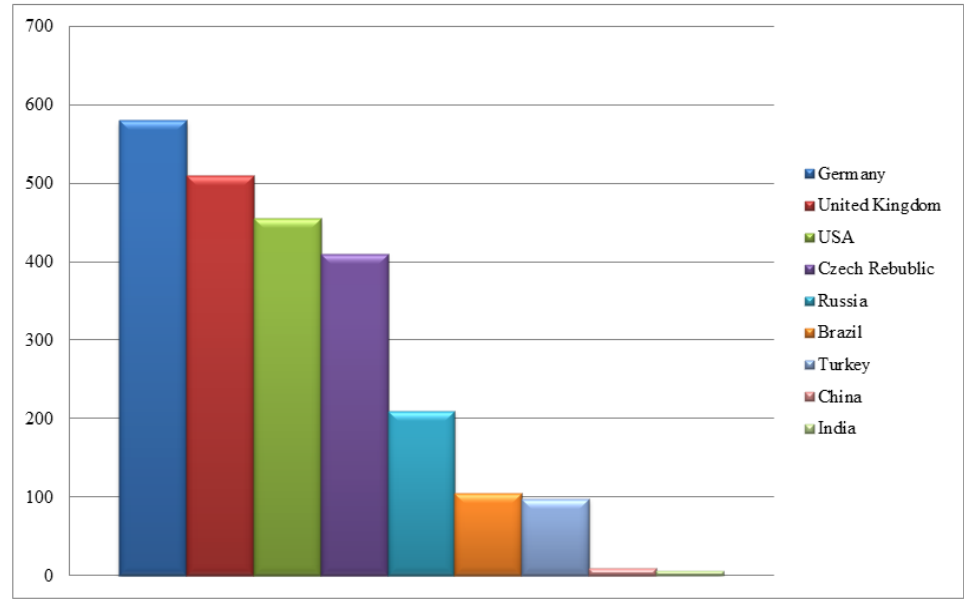

Fig. 1. World motorization of the population.

\section{Experimental section}

The analysis of the indicators of the regular transport movement of the population in Moscow (Fig. 2) shows that most of the movement is carried out by public transport, the population of the city strives to reduce the time and financial costs of movement [3]. There is also a trend of pedestrian traffic in the center of the city and a very small percentage of the exploitation of personal vehicles (first of all, this is due to the increase in prices for parking fees in the center of the capital).

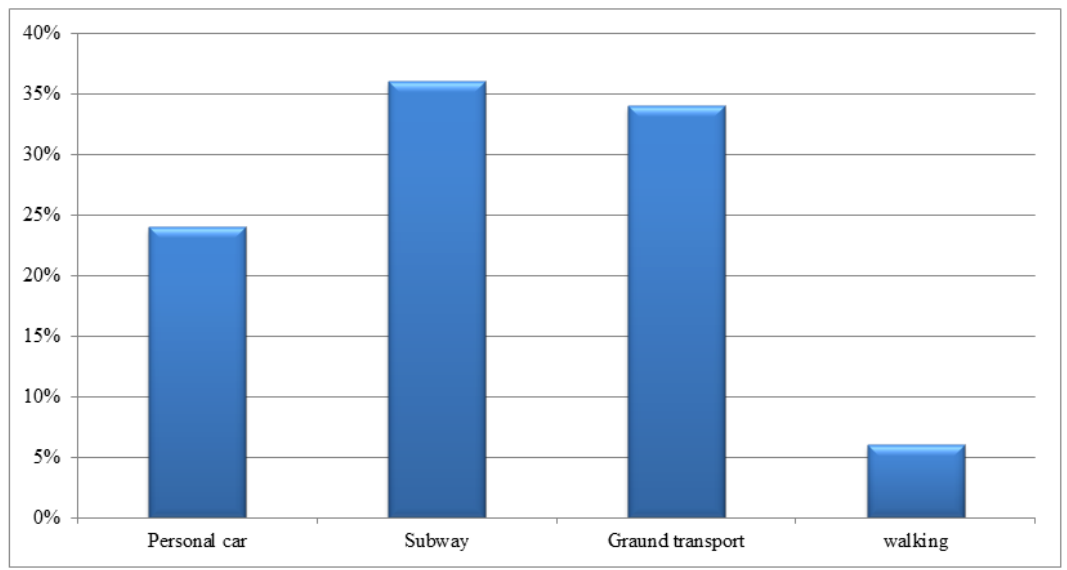

Fig. 2. Comparative analysis of indicators of regular transport movement in Moscow.

The analysis showed that at a relatively low percentage of the use of personal vehicles, the level of congestion of road networks and motorways in Moscow is much higher than in many European cities (Fig. 3). 


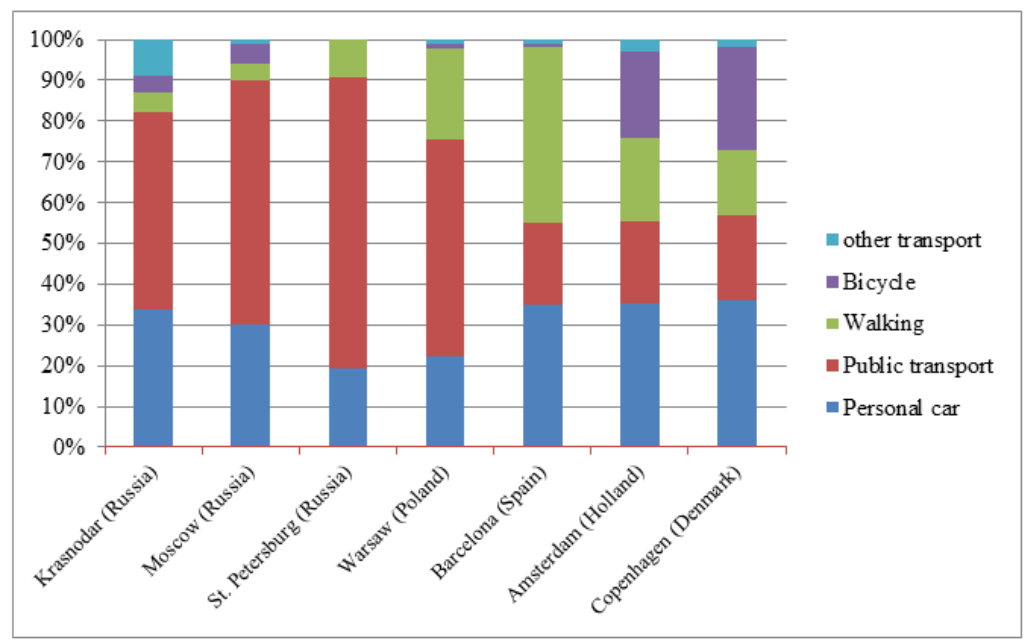

Fig. 3. Comparative analysis of the use of vehicles for different cities.

\section{Result section}

Based on the sociological survey conducted by the population, it can be concluded that the main reason for using personal vehicles is related to the service function: increased comfort of travel and the desire to shorten the travel time is also not unimportant for the distance from the place of work (Fig. 4).

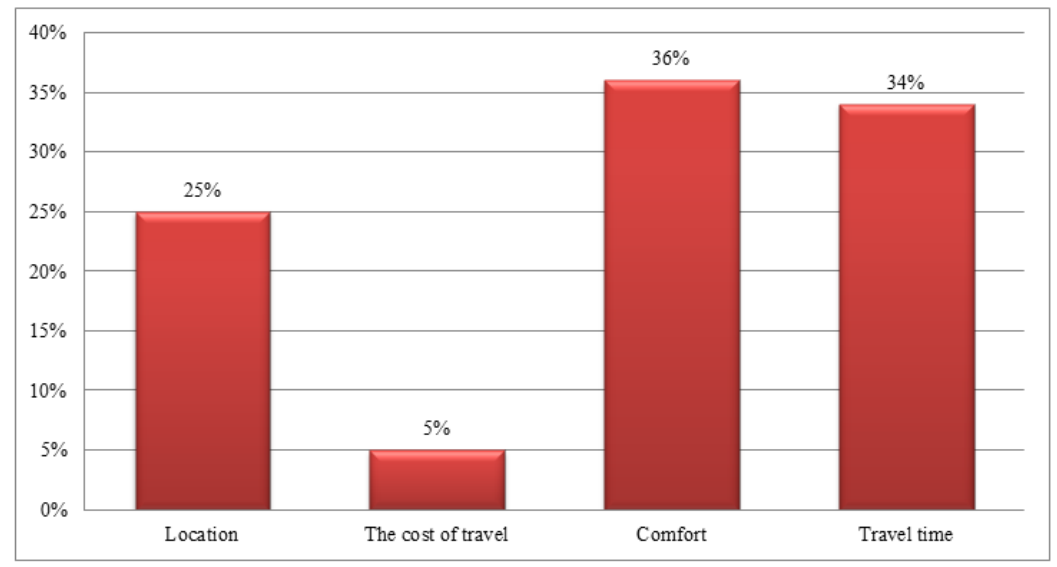

Fig. 4. Results of a public opinion poll on the reasons for using personal vehicles in Moscow.

Also, a sociological poll showed that about $54 \%$ of respondents prefer to park for free on the street, which creates additional traffic and congestion during peak periods [4-5].

In Fig. 5 presents data according to which the current situation with parking places in Moscow is perceived by respondents as unsatisfactory. 


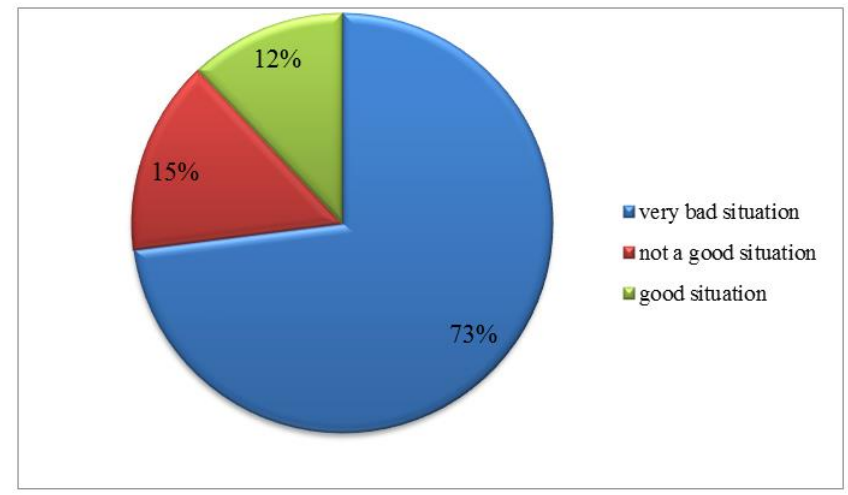

Fig. 5. Respondents' assessment of the current situation with parking spaces.

Along with the creation of multi-level mechanized parking spaces, another variant of the solution to this problem is intercept parking [6]. Intercepting parking allows drivers to leave their cars in specially allocated parking spaces located at the entrances to the city and near the third transport ring and provide a comfortable transfer for public transport.

\section{Discussion}

Nowadays, the implementation of projects of office real estate of Class A and B is impossible without an exact calculation of the areas necessary for the organization of parking spaces [7]. However, in Moscow there is a huge fund of buildings, reconstructed for office space, in which parking spaces are not available, often there are not enough parking spaces even for the company's top management. The availability of parking spaces in Moscow is no more than $10 \%$ of the required number. The total area of buildings reconstructed in Moscow for offices and various is about $14-16$ million square meters. $\mathrm{m}$, which is $48 \%$ of the total market for office real estate in Moscow [8-9].

At the same time, in some old mansions there are parking lots in the center of Moscow, but very limited in their capacity (for example, an office building with a total area of 1.5 thousand sq. M can have only 5 parking spaces). This is due to the fact that during the reconstruction or major repairs of architectural monuments there are no obligations to build additional parking spaces [10]. But due to the current market requirements, many development companies solve this problem of the lack of parking spaces for the construction of a separate structured parking, capable of simultaneously accepting about 700 cars (for example, the Krugozor business center, Obrucheva Street (Fig.7)).

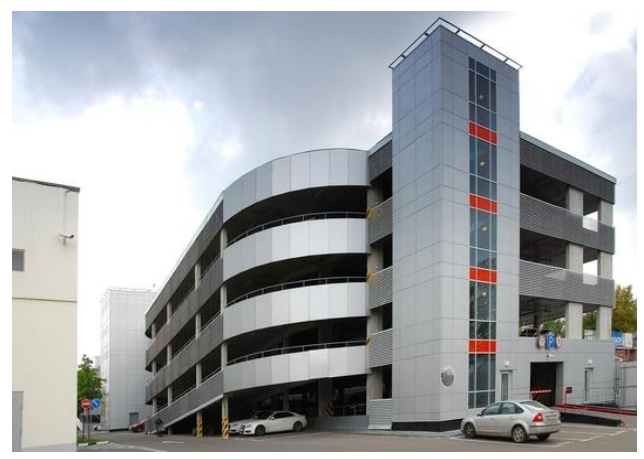

Fig. 7. Business Center "Krugozor", st. Obrucheva. 
In comparison with Russia, a wide range of various parking equipment is presented in the USA, Europe and Asia (from the simplest mechanical parking lots to fully automated systems). The use of such mechanisms will make it possible to effectively solve the problem of acute shortage of parking spaces in Russia, increase the carrying capacity of roads, modernize the architectural appearance of the city and create more comfortable living conditions in the city [11].

The largest Indian developer of commercial real estate, DLF, in 2011, acted as a private concessionaire in charge of construction and operation, and introduced several fully automated vehicle parking systems in New Delhi (two of which are currently in operation).

The first parking system for 824 cars is located in a shopping complex in Sarojini Nagar (India), put into operation in early 2012. The average volume of service is $178 \mathrm{cars} / \mathrm{h}$, at the same time the system is capable of taking 104 cars and issuing 74 units each. On average, the parking lot is $80 \%$ full, and during rush hour a line of arriving cars is built far beyond the parking lot [12].

Today China is the undisputed leader in the field of parking systems. In the city of Xiamen is implemented a city program to increase parking space, near the Sheraton Xiamen Hotel officially put into operation the first complex of mechanized parking systems of the tower type for 285 storage places. At the loading level, vehicles are transferred to the mechanized device that moves them, without any participation of people at the storage sites, the time required to complete this process does not exceed 2 minutes. In addition, it is planned to build 16 more similar facilities with a total capacity of 6,500 places located in different parts of the city, where there is an increased business activity of the population [13].

In Canada, it is planned to build the second fully-automated parking system for modular cars in 57 parking spaces in the country, which will save up to $65 \%$ of the parking space, according to the representation of the Canadian construction company Windmill Development Group. This company is one of the first who introduced electronic communications for the management of a private car inside the parking system [14].

In the province of Alberta in Canada, discusses a program plan for the restoration in the historic center of a number of ancient buildings collapsing. According to the representative of the organization for the preservation of the architectural heritage of Neil Richardson, these buildings, which are perceived as a slum in the heart of the city, can revive the project to build a 14-story automatic parking lot designed for 388 storage places [15].

In early 2015, the data in the Guinness Book of Records was updated on the world's largest fully automated parking system. This system is a 2 tower located in Wolfsburg and is one of the tourist attractions of the city. Each tower is a 25 -storey, fully automated building, $48 \mathrm{~m}$ high, capable of accommodating up to 400 cars at the same time. Cars park and leave the building with two special elevators. In 2014, Autostadt towers were included in the Guinness Book of World Records as "the fastest automatic parking system in the world" thanks to the speed of the elevator - $2 \mathrm{~m}$ per second. The new car rises from the entrance to the highest parking place in just 1 minute and 44 seconds (Fig. 8-9).
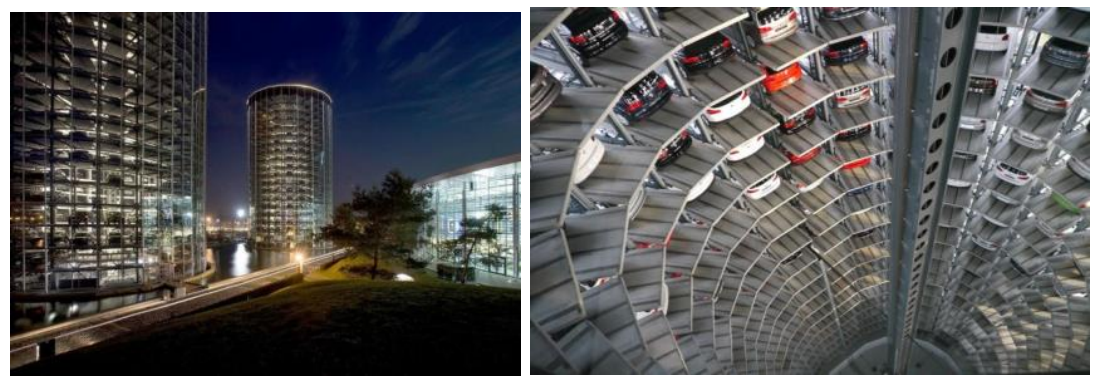

Fig. 8. Towers Autostadt, Wolfsburg, Germany. 
The experience of foreign scientists, designers and engineers is undoubtedly useful when planning parking spaces, designing and arranging parking systems.

\section{References}

1. A. Orlov, I. Chubarkina, IOP Conf. Series: Materials Science and Engineering 365, 022019 (2018)

2. I. Bahirev, S. Kanep, N. Karmadonova, Town planning 5(39), 20-23 (2015)

3. N. Danilina, D. Vlasov, MATEC Web of Conferences 5, 05017 (2016)

4. R. Alidad, International Scientific Review 17(27), 45-48 (2016)

5. L. Manukhina, MATEC Web of Conferences 170, 01133 (2018)

6. P. Grabovy, A. Orlov, Procedia Engineering 153, 195-202 (2016)

7. M. Sharov, A. Mikhailov, Transportation Research Procedia, 591-595 (2017)

8. D. Vlasov, E3S Web of Conferences, 01012 (2016)

9. A.G. Levashev, A.Yu. Mikhailov, I.M. Golovnykh, WIT Transactions on Ecology and the Environment 2, 1067 (2013)

10. O. Kurakova, MATEC Web of Conferences 170, 01105 (2018)

11. I. Bahirev, Arhitektura. Stroitel'stvo. Dizajn 3, 60-63 (2008)

12. A. Menshutin, D. Vlasov, N. Danilina, The development of intermodal transport services on the basis of geoanalytical information, ITM Web of Conferences (2016)

13. M. Kostyshak, M. Lunyakov, IOP Conf. Series: Energy Management of Municipal Transportation Facilities and Transport 19, 012183 (2017)

14. I. Bahirev, Transport construction 10, 2-5 (2008)

15. A. Levashev, A. Mikhailov, I. Golovnykh, WIT Transactions on Ecology and the Environment 179 (2), 1067-1076 (2014) 